\title{
Jogo de cartas como estratégia para o ensino de doenças autoimunes na graduação médica
}

\section{Card game as strategy for the teaching of autoimmune diseases in medical graduation}

\section{Juego de cartas como estrategia para la enseñanza de enfermedades autoinmunes en la graduación médica}

Catarina Joelma Magalhães Braga ${ }^{1, a}$

catarina braga1976@yahoo.com.br | https://orcid.org/0000-0002-0306-7257

Lydia Dayanne Maia Pantoja ${ }^{1, b}$

lydia.pantoja@uece.br | https://orcid.org/o0oo-0002-4446-7230

Tatiana Paschoalette Rodrigues Bachur,c

tatiana.bachur@uece.br | https://orcid.org/oooo-0002-1975-9995

Gislei Frota Aragã $0^{1, d}$

gislei.frota@uece.br | http://orcid.org/o000-0002-0689-8371

${ }^{1}$ Universidade Estadual do Ceará. Fortaleza, CE, Brasil.

a Doutorado em Parasitologia pela Universidade de São Paulo.

${ }^{b}$ Doutorado em Engenharia Civil pela Universidade Federal do Ceará.

c Mestrado em Patologia pela Universidade Federal do Ceará.

${ }^{\mathrm{d}}$ Doutorado em Farmacologia pela Universidade Federal do Ceará.

\section{Resumo}

A experiência relatada neste artigo envolveu a elaboração e aplicação do ImunoDAI, um jogo de cartas desenvolvido por alunos e professores do curso de Medicina para abordar o conteúdo técnico de vinte Doenças Autoimunes (DAI). As DAI compreendem numerosas doenças com diferentes apresentações clínicas que compartilham uma etiologia complexa, porém comum, representada pela resposta imunológica contra autoantígenos. O ImunoDAI trata-se de um jogo produzido coletivamente que, enquanto recurso pedagógico, possibilitou o trabalho com as DAI por meio da elaboração de quatro cartas contendo informações sobre as principais causas da doença; imunopatogênese; sinais e sintomas; diagnóstico e tratamento. A utilização do jogo facilitou a fixação dos conteúdos e favoreceu o processo de ensino-aprendizagem ao permitir múltiplas interações, promover a aprendizagem dos conteúdos, desenvolver autonomia, criatividade, cooperação mútua, discussões e tomadas de decisões, habilidades indispensáveis aos futuros médicos.

Palavras-chave: Doenças autoimunes; Metodologias ativas; Recurso pedagógico; Jogo de cartas; Jogos pedagógicos; Jogos colaborativos; Jogos concretos; Habilidades cognitivas. 


\title{
Abstract
}

The experience reported in this article involved the development and application of ImmunoDAI, a card game developed by students and professors of the medical course to address the technical content of twenty autoimmune diseases (DAI). The DAI comprise numerous diseases with different clinical presentations that share a complex but common etiology represented by the immune response against autoantigens. The ImunoDAI is a collectively produced game that, as a pedagogical resource, made possible the work with the DAI through the elaboration of four letters containing information about the main causes of the disease; immunopathogenesis; signals and symptoms; diagnosis and treatment. The use of the game facilitated the fixing of contents and favored the teaching-learning process by allowing multiple interactions, promoting content learning, developing autonomy, creativity, cooperation, discussions and decision making, skills that are indispensable for future doctors.

Keywords: Autoimmune diseases; Active methodologies; Pedagogical resource; Cards game; Educational games; Collaborative games; Concrete games; Cognitive abilities.

\section{Resumen}

A experiencia relatada en este artículo involucró la elaboración y aplicación del ImunoDAI, un juego de cartas desarrollado por alumnos y profesores del curso de Medicina para abordar el contenido técnico de veinte Enfermedades autoinmunes (DAI). Las DAI comprenden numerosas enfermedades con diferentes presentaciones clínicas que comparten una etiología compleja, pero común, representada por la respuesta inmunológica contra autoantígenos. El ImunoDAI es un juego producido colectivamente que, en cuanto recurso pedagógico, posibilitó el trabajo con las DAI por medio de la elaboración de cuatro cartas conteniendo informaciones sobre las principales causas de la enfermedad; inmunopatogenia; signos y síntomas; diagnóstico y tratamiento. La utilización del juego facilitó la fijación de los contenidos y favoreció el proceso de enseñanza-aprendizaje al permitir múltiples interacciones, promover el aprendizaje de los contenidos, desarrollar autonomía, creatividad, cooperación, discusiones y tomas de decisiones, habilidades indispensables para los futuros médicos.

Palabras clave: Enfermedades autoinmunes; Metodologías activas; Recurso pedagógico; Juego de cartas; Juegos pedagógicos; Juegos colaborativos; Huegos concretos; Habilidades cognitivas.

INFORMAÇÕES DO ARTIGO

\author{
Contribuição dos autores: \\ Concepção e desenho do estudo: Catarina Joelma Magalhães Braga. \\ Aquisição, análise ou interpretação dos dados: Catarina Joelma Magalhães Braga. \\ Redação do manuscrito: Catarina Joelma Magalhães Braga, Lydia Dayanne Maia Pantoja, Tatiana Taschoalette Rodrigues Bachur e \\ Gislei Frota Aragão. \\ Revisão crítica do conteúdo intelectual: Catarina Joelma Magalhães Braga e Janaína Bacelo de Figueiredo.
}

Declaração de conflito de interesses: não há.

Fontes de financiamento: não houve.

Considerações éticas: não há.

Agradecimentos/Contribuições adicionais: os autores agradecem a Janaína Bacelo de Figueiredo, Mestre em Letras pela Universidade Federal do Paraná, pelos comentários e sugestões.

Histórico do artigo: submetido: 2 maio 2018 | aceito: 5 jun. 2019 | publicado: 12 set. 2019.

Apresentação anterior: não houve.

Licença CC BY-NC atribuição não comercial. Com essa licença é permitido acessar, baixar (download), copiar, imprimir, compartilhar, reutilizar e distribuir os artigos, desde que para uso não comercial e com a citação da fonte, conferindo os devidos créditos de autoria e menção à Reciis. Nesses casos, nenhuma permissão é necessária por parte dos autores ou dos editores. 


\section{Introdução}

A exigência de um domínio cada vez maior de conhecimentos e habilidades técnicas nos cursos das áreas da saúde impõe que novas metodologias de ensino e instrumentos educativos sejam utilizados como alternativa para facilitar o processo de ensino-aprendizagem e amenizar o estresse e o cansaço dos alunos diante da excessiva carga de conteúdos e horas em sala de aula.

A disciplina que motivou a criação da prática pedagógica que será aqui apresentada foi a Imunologia, uma área das ciências biomédicas que estuda o sistema imunológico - um conjunto de células, órgãos e tecidos que, de forma coordenada e sincronizada, age para defender o corpo de patógenos invasores. Essa especialidade se ocupa de estudar os mecanismos pelos quais o sistema imunológico mantém o estado de saúde de um organismo, bem como as desordens ou falhas desse sistema, as quais conduzem a doenças autoimunes (DAI), alergias, imunodeficiências, cânceres ou levam à rejeição de órgãos transplantados ${ }^{1-2}$.

Tantas foram as descobertas nessa área que o conhecimento sobre essa ciência vem se acumulando de forma extraordinária. Por conseguinte, o pouco contato dos alunos na educação básica com essa área do conhecimento, aliado ao extenso conteúdo, à complexidade da linguagem técnica e dos mecanismos moleculares envolvidos, bem como o pouco tempo para o trabalho com tais conteúdos, têm se constituído um grande obstáculo para que o aluno efetivamente assimile e aplique os conhecimentos da disciplina de Imunologia em seu cotidiano acadêmico.

Diante de tal cenário, torna-se necessário o investimento em práticas pedagógicas que favoreçam o processo de ensino-aprendizagem, sistematizando o extenso conteúdo para uma melhor aprendizagem dos alunos. É nesse contexto que os jogos surgem como uma poderosa ferramenta pedagógica facilitadora da compreensão e da assimilação de conteúdos de alta complexidade, promovendo a interação entre os alunos, entre os alunos e o conteúdo e entre os alunos e o professor.

Conforme Miranda ${ }^{3}$, o jogo didático permite alcançar diversos objetivos pedagógicos relacionados a diferentes áreas do desenvolvimento. Em relação à cognição, favorece o desenvolvimento da inteligência e da personalidade, fundamentais para a construção de conhecimento. No que diz respeito ao plano afetivo, contribui para o desenvolvimento da sensibilidade, estreitando os laços de amizade e, consequentemente, desenvolvendo a afetividade. Os jogos também favorecem o exercício da socialização, ao promover vivências em grupo, e o estímulo da motivação, ao solicitar o envolvimento do sujeito na ação, desafiando-o e mobilizando sua curiosidade e criatividade.

É crescente o interesse no desenvolvimento de estratégias lúdicas como facilitadoras do processo de ensino-aprendizagem em diferentes áreas de conhecimento e níveis de ensino. No que diz respeito à educação básica, estratégias de ensino que favoreçam a aprendizagem já vêm sendo pesquisadas e aplicadas de forma mais sistemática, o que não ocorre no ensino superior de forma corriqueira. Diante dessa lacuna, faz-se necessário desenvolver e apresentar experiências vivenciadas no ensino superior. No caso contemplado neste artigo, temos a elaboração e a aplicação de um instrumento pedagógico no formato de um jogo de cartas - o ImunoDAI - para ministrar os conteúdos sobre 'Doenças Autoimunes'.

A complexidade dos mecanismos imunológicos envolvidos na iniciação e manutenção das doenças autoimunes, bem como a diversidade de sinais e sintomas apresentados nessas patologias, acabam por confundir e dificultar a assimilação dos conteúdos pelos alunos. Além disso, este tema mostrou-se particularmente interessante por permitir ao professor correlacionar todo o conteúdo abordado na disciplina MAD-Imunologia básica de uma forma integrada, aplicada e contextualizada com a clínica. A experiência com o jogo ImunoDAI revela como conteúdos de grande complexidade podem ser abordados de forma prática, ativa, interdisciplinar e prazerosa, permitindo ao professor não somente apresentar os conteúdos disciplinares, mas também desenvolver habilidades técnicas, cognitivas, sociais e emocionais nos educandos. 
Destarte, este artigo tem o objetivo de relatar a experiência vivenciada durante a elaboração e aplicação do jogo de cartas denominado ImunoDAI. O jogo em questão foi elaborado pelos alunos do curso de Medicina como parte das atividades da disciplina de Mecanismos de Agressão e Defesa no módulo de Imunologia Básica (MAD-Imunologia Básica) e aborda os conteúdos sobre doenças autoimunes (DAI) de forma técnica, objetiva e lúdica. A criação e a aplicação dessa prática pedagógica tiveram como intenção facilitar o processo de ensino-aprendizagem do complexo conteúdo sobre DAI, promovendo o raciocínio multidisciplinar, a criatividade, a autonomia e as interações interpessoais.

A proposta de elaboração e apresentação do jogo de cartas denominado ImunoDAI foi realizada pela professora da disciplina após os alunos participarem de uma aula expositiva tradicional sobre 'Bases Moleculares da Autotolerância e Autoimunidade' e foi impulsionada pela importância e pela complexidade deste tema diante da falta de tempo para abordar as principais doenças autoimunes (DAI) de forma proveitosa para os alunos.

\section{Metodologia}

Este tópico tem por objetivo descrever os procedimentos metodológicos que foram utilizados na elaboração de um jogo educativo e visa detalhar todas as etapas do processo, desde os fatores que impulsionaram seu desenvolvimento, seleção dos conteúdos, padronização e elaboração das cartas e regras do jogo até a sua execução. O jogo ImunoDAI foi construído e executado pelos alunos do terceiro semestre do curso de Medicina de uma universidade pública, como atividade pedagógica da disciplina de Mecanismos de Agressão e Defesa (Módulo Imunologia Básica), com o objetivo de promover a fixação e integração dos conteúdos sobre Doenças Autoimunes e permitir o desenvolvimento de habilidades cognitivas nos educandos. Nesse sentido, desenvolveu-se uma pesquisa qualitativa, utilizando a própria sala de aula como ambiente de estudo. A coleta de dados foi realizada mediante a observação direta dos alunos durante a execução do jogo, dos materiais produzidos e dos depoimentos emitidos pelos alunos, em que descreveram suas dificuldades e facilidades na elaboração e execução do jogo, sendo essa experiência compartilhada por meio deste artigo.

\section{Construção do jogo}

\section{Seleção do conteúdo didático para a construção do jogo de cartas ImunoDAI}

A seleção do conteúdo a ser abordado foi de fundamental importância para o desenvolvimento do jogo. Dentre as mais de cem DAI existentes, foram selecionadas apenas vinte (Quadro I). Utilizou-se como critério de seleção as DAI comuns ou aquelas cujos mecanismos imunológicos estão completamente ou parcialmente dissecados. A seleção de um número reduzido de doenças se deu em virtude do número de alunos e do tempo disponível para a realização da atividade.

As informações utilizadas para a confecção das cartas foram coletadas pelos alunos em livros, artigos acadêmicos e demais manuais técnicos pertinentes da área ${ }^{8-9}$. Além disso, foi previamente estabelecido com os alunos que os conteúdos de interesse deveriam ser abordados de acordo com as regras previamente estabelecidas pela professora da disciplina (item 2.1.2 da seção de metodologia). 
Quadro 1- Lista das doenças autoimunes contempladas no jogo de cartas ImunoDAl, Fortaleza, 2018

\section{Doenças Autoimunes}

01- Anemia hemolítica autoimune
02- Anemia perniciosa autoimune
03- Artrite reumatoide
04- Febre Reumática
05- Diabetes melito tipo I
06- Doença de Graves
07- Doença de Crohn
08- Doença celíaca
09- Esclerose múltipla
10- Espondilite anquilosante

11- Granulomatose de Wegener

12- Síndrome de Guillan Barré

13- Hepatite autoimune

14- Lúpus eritematoso sistêmico

15- Miastenia Gravis

16- Pênfigo vulgar

17- Púrpura trombocitopênica autoimune

18- Psoríase

19- Síndrome de Goodpasture

20- Tireoidite de Hashimoto

Fonte: Os autores (2018).

\section{Confecção das cartas do jogo ImunoDAI}

As cartas do jogo ImunoDAI foram elaboradas pelos alunos do terceiro semestre do curso de medicina da Universidade Estadual do Ceará (UECE) como atividade pedagógica avaliativa da disciplina MADImunologia Básica. Após a seleção do conteúdo a ser abordado, foram definidos os critérios para a elaboração e apresentação das cartas, ficando acordado com os alunos que esta atividade seria avaliativa e que sua pontuação seria distribuída da seguinte forma: 5 pontos para a elaboração das cartas, 1 ponto para a apresentação das cartas e 4 pontos para a participação no jogo.

Para a elaboração das cartas, os quarenta alunos da turma foram divididos em vinte duplas, sendo sorteada, para cada dupla, uma doença autoimune do quadro I. As cartas foram elaboradas segundo as orientações e especificações da professora, de modo que para cada uma das vinte doenças autoimunes selecionadas, foi solicitado que os alunos elaborassem quatro cartas contendo as seguintes informações: carta 1 - principais causas da doença; carta 2 - imunopatogênese; carta 3 - sinais e sintomas; carta 4 diagnóstico e tratamento da doença autoimune. O jogo, em sua versão final, contou com um total de oitenta cartas. A Figura I mostra um conjunto de quatro cartas elaboradas para o jogo.

Visando a padronização das cartas, foram estabelecidas duas regras principais e um modelo para a sua confecção. A primeira regra era não expor, em qualquer uma das cartas, o nome da doença ou sua abreviação. A segunda determinava que o conteúdo das cartas deveria ser abordado por meio de ilustrações (desenhos ou fotografias), tabelas, fluxogramas e/ou escrita objetiva para facilitar a visualização e leitura das informações. Para estabelecer uma padronização, os alunos receberam um arquivo em Power Point contendo um modelo para a elaboração das cartas (medidas $10 \mathrm{~cm} \mathrm{X} \mathrm{15cm)} \mathrm{e} \mathrm{as} \mathrm{especificações} \mathrm{de} \mathrm{formatação}$ (título em caixa alta, fonte Arial, tamanho 24, em negrito, centralizado e corpo do texto em fonte Arial, tamanho 20, justificado), espaçamento simples. Também foi determinado que a impressão das cartas deveria ser feita em papel $80 \mathrm{~kg}$ de cor branca. 


\section{SINAIS E SINTOMAS}

- Sinais: Diarreia ou constipação, fadiga, perda de apetite, palidez, língua inchada ou avermelhada, sangramento de gengivas e acometimento do sistema nervoso.

- Sintomas: confusão mental, parestesias, entorpecimento das mãos e dos pés, depressão.

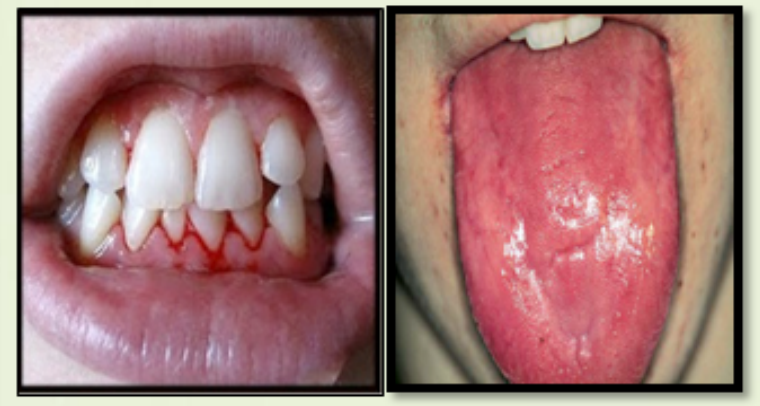

\section{IMUNOPATOGÊNESE}

- Anticorpos que deveriam proteger nosso corpo de agentes invasores acabam ligando-se ao $\mathrm{FI}$, bloqueando sua absorção, ou se ligam a células parietais causando sua destruição.

- Caracteriza-se por inflamação crônica do fundo e corpo gástrico e pela reação autoimune dirigida às células parietais.

- Não há mais absorção da vit. B12.

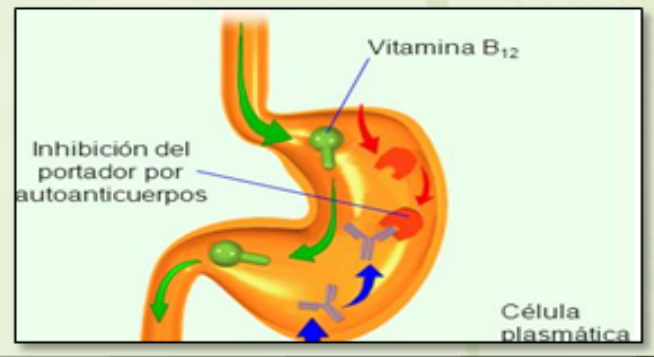

\section{CAUSAS}

- Ausência do fator intrínseco (FI)proteína necessária para a absorção de vitamina B12 no TGI.

- Deficiência do FI motivada por: Má nutrição, fatores hereditários, doença celíaca, cirurgia bariátrica, enfraquecimento do revestimento interno do estômago.

- A carência da vitamina justifica o quadro clínico da doença.

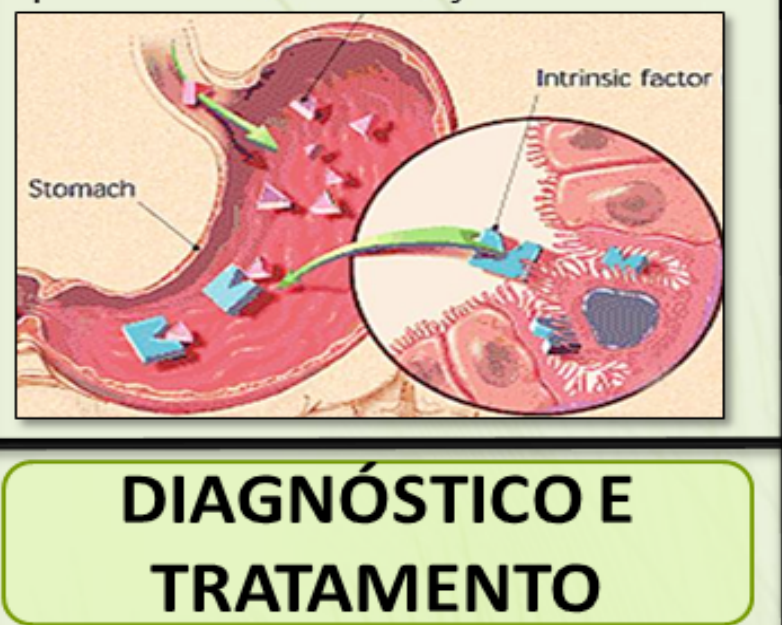

- Exames laboratoriais: Exame da medula óssea, contagem sanguínea, contagem de reticulócitos, teste de Schilling, nível de vitamina B12.

- Técnicas de imunofluorescência indireta: anticorpos séricos contra as células gástricas parietais.

- Autoanticorpos contra o fator intrínseco: autoanticorpos tipo I, que bloqueiam a ligação da vitamina B12 ao fator intrínseco e autoanticorpos tipo II que se ligam a um sítio remoto ao de ligação da vitamina B12.

- Tratamento: injeções intramusculares de vitamina B12 ou administração oral.

Figura 1 - Cartas do jogo ImunoDAI contendo informações sobre principais causas, imunopatogênese, sinais e sintomas, diagnóstico e tratamento da anemia perniciosa Fonte: Os autores (2018). 


\section{Execução do ImunoDAl em sala de aula}

\section{Apresentação das cartas do ImunoDAI}

Após o sorteio do conteúdo, os alunos tiveram uma semana para entregar as cartas confeccionadas de acordo com as normas estabelecidas no item 2.1.2 e as apresentaram aos demais colegas utilizando-se de um projetor Epson (PowerLite S41). Para a organização dessa etapa, a professora pré-selecionou a ordem de apresentação das DAI de forma que algumas doenças com similaridades de mecanismos imunopatológicos, como por exemplo a tireoidite de Hashimoto e a doença de Graves, fossem apresentadas em sequência para facilitar a identificação de similaridades e diferenças entre elas.

Ao final das apresentações foi dado um intervalo de quinze minutos, e a turma foi dividida em duas grandes equipes de 20 alunos, denominadas Equipe A e Equipe B. As duplas que confeccionaram as cartas foram separadas em equipes diferentes, pois dessa forma poderiam auxiliar o grupo com informações sobre a DAI que foi estudada para a confecção das cartas, garantindo, assim, a dinâmica do jogo e favorecendo a aprendizagem de todos.

\section{Regras para execução do jogo ImunoDAI}

Para a execução do jogo, primeiramente foi escolhido um líder de cada equipe para ficar responsável por segurar e movimentar as cartas. Os demais alunos foram orientados a ficarem próximos ao líder, com o objetivo de discutirem e executarem coletivamente as estratégias para a atividade.

Antes de iniciar o jogo, a seguintes regras foram estabelecidas junto aos dois grupos: as cartas devem ser embaralhadas e empilhadas sobre a mesa onde os jogadores ocupam lugares opostos. Quatro cartas devem ser distribuídas para cada equipe. O jogo inicia quando o líder de uma das equipes puxar uma carta da 'pilha'. Ele deve decidir com sua equipe se fica ou não com a carta e, em qualquer uma das opções, o grupo deve descartar uma carta na mesa de modo que durante todo o jogo o grupo fique sempre com quatro cartas nas mãos. A carta descartada poderá ser a mesma que foi puxada ou outra que esteja em mãos e que não faz par com as demais cartas/DAI. A carta descartada poderá ser adquirida por outra equipe que, ao pegá-la, também deverá descartar uma carta imediatamente. As cartas descartadas pelas equipes devem ser empilhadas para formar o 'descarte'. Cada equipe só poderá pegar uma carta do descarte por vez, sendo essa a última que foi descartada. Após cada equipe pegar e descartar uma carta deverá ser iniciada uma nova rodada até que haja uma equipe vencedora.

O objetivo do jogo ImunoDAI é agrupar a sequência de quatro cartas pertencentes a uma mesma DAI. Assim, ganhará o jogo a equipe que reunir as quatro cartas primeiro, sendo que estas devem representar, de forma correta, uma única DAI. A equipe que montar primeiro as quatro cartas deve gritar 'bati' e explicar, sem ler, todas as características da DAI formada para o professor e demais alunos, os quais devem ratificar se a DAI formada está correta. Caso uma equipe finalize o jogo reunindo as quatro cartas, mas confunda uma das cartas com a de outra doença, errando a sequência e, consequentemente, a definição da doença, a equipe deverá descartar todas as suas cartas, colocando-as sob o 'descarte' e reiniciar o jogo pegando quatro novas cartas da 'pilha'.

O jogo ImunoDAI foi pensado para favorecer a interação entre os alunos, por isso deve ser jogado de forma coletiva, formando-se de dois a quatro grupos. Para isso, os membros da equipe devem participar ativamente do jogo-aula e colaborar na tomada de decisões. 


\section{Relato de experiência e reflexões sobre os resultados alcançados}

\section{A experiência da construção coletiva do jogo}

A experiência de utilização do jogo ImunoDAI como recurso pedagógico iniciou com a elaboração e a apresentação das cartas pelos alunos da disciplina e finalizou com a participação deles no jogo. Na etapa de elaboração, verificou-se que alguns alunos apresentaram dificuldades com a impressão das cartas, de modo que duas duplas plastificaram suas cartas, as quais tiveram que ser retiradas do jogo, pois seriam facilmente identificadas. Além disso, os recursos gráficos (figuras, imagens, tabelas e esquemas) apresentaram-se pouco padronizados já que foram retirados de fontes distintas, mas isso não prejudicou o desenvolvimento do jogo ou promoveu a fácil identificação das cartas quando estas foram misturadas com as demais.

A construção das cartas pelos próprios alunos foi vislumbrada como uma forma de promover o engajamento e estimular a criatividade dos educandos, entre outras habilidades, pois, como afirma Moratori ${ }^{4}$, "O jogo pode ser considerado como um importante meio educacional, pois propicia um desenvolvimento integral e dinâmico nas áreas cognitiva, afetiva, linguística, social, moral e motora, além de contribuir para a construção da autonomia, criticidade, criatividade, responsabilidade e cooperação das crianças e adolescentes".

Na literatura sobre a utilização de jogos concretos em ambiente acadêmico, é possível observar que os jogos são frequentemente construídos pelos professores, e os alunos recebem os materiais prontos para utilização $0^{5-9}$. Tal prática apresenta vantagens e desvantagens, pois, como aborda Araújo e colaboradores ${ }^{10}$, é importante "considerar que os adolescentes, no processo de elaboração dos jogos, foram presenças significativas, sendo constantemente realçada sua capacidade criativa pelas ideias apresentadas e lucidez evidenciadas nas tomadas de decisões frente as dúvidas e questionamentos surgidos". Entre as vantagens da elaboração do jogo pelo professor estão a completa padronização dos recursos gráficos e textuais, elevada qualidade visual do material e de seus componentes, além da segurança sobre os conteúdos apresentados. Entretanto, a principal desvantagem reside no fato de que as várias etapas da elaboração do jogo oportunizam o desenvolvimento de habilidades técnicas, como pesquisar e selecionar os conteúdos do jogo, elaborar gráficos, quadros e tabelas, selecionar e desenvolver materiais. Habilidades cognitivas, sociais e emocionais também são oportunizadas, como a capacidade de discussão, argumentação, negociação e tomada de decisão, apreensão dos conteúdos, segurança, desenvoltura e espírito de equipe. Quando o jogo é entregue pronto para o aluno essas etapas são subutilizadas. Por outro lado, ao optar em construir o jogo junto com os alunos, o professor deve fornecer todo o suporte necessário para a elaboração, incluindo tempo para a execução do projeto, sob pena de causar estresse, insatisfação e desmotivação.

A participação dos alunos no processo de criação do jogo valoriza esse instrumento revestindo-o de significados de apropriação, utilidade, pertencimento e prazer. Para Araújo e colaboradores ${ }^{10}$, essa experiência refletiu-se na "alegria dos adolescentes, quando visualizaram a arte final dos jogos, pelo valor de sua contribuição [...]”. Além disso, para estes mesmos autores, "A inclusão dos adolescentes, nesse momento, reafirma que quando mobilizados trazem em si o exercício do prazer, da alegria, da felicidade, importantes elementos de integração e experimento de vida de efeito uns sobre os outros, o que não excluiu, em nenhum instante, a reflexão da AIDS [...]”, doença trabalhada no jogo em questão.

O tempo de aula disponibilizado para a aplicação desta metodologia foi de três horas e 35 minutos (não incluído o tempo da apresentação final da equipe vencedora e demais interferências), sendo que a organização do tempo pedagógico para a realização da atividade se deu em etapas. Para a apresentação das cartas foram destinadas duas horas, e para a organização da sala, formação das equipes e explicação das regras do jogo foram destinados vinte minutos. O tempo de execução do jogo em si foi de uma hora e 15 minutos. 
A apresentação das cartas do jogo ImunoDAI ocorreu previamente à execução do jogo, e sua organização foi explicitada no item 2.2.1. Cabe aqui salientar que a organização do jogo como um todo não deixou de levar em consideração a especificidade do conteúdo a ser trabalhado. As estratégias foram pensadas de forma que não colocassem o exercício lúdico acima da coerência e/ou da sequência lógica dos conteúdos ministrados.

Ainda obedecendo a essa lógica de não privilegiar o jogo em relação ao conteúdo, a prévia apresentação das cartas foi pensada pela professora como um recurso pedagógico que possibilitasse aos alunos compartilharem o aprendizado adquirido durante a pesquisa e a elaboração do material. Essa etapa foi imprescindível, pois como o conteúdo a ser trabalhado totalizava vinte doenças autoimunes, seria impossível para os alunos estudarem e assimilarem seus conteúdos e repercussões clínicas em apenas uma semana. Nesta etapa os alunos não demonstraram nenhuma dificuldade ou desconforto, uma vez que a apresentação de seminários e relatórios são atividades constantes em sua rotina acadêmica. Outra reflexão importante a ser feita sobre essa etapa da atividade é que, embora os alunos possam estar familiarizados com apresentações orais, muitas vezes há dificuldade na organização do conteúdo para o exercício da oralidade. Habilidades como a seleção de informações importantes no material de pesquisa e a capacidade de síntese foram exercitadas, uma vez que o espaço nas cartas era limitado e a escolha do conteúdo teve que ser feita de maneira pontual e sistematizada.

O exercício descrito acima desencadeou uma primeira mudança no comportamento dos alunos, pois durante a apresentação das cartas eles se mostraram muito mais atentos e participativos, em comparação à apresentação de seminários tradicionais. Tal fato pode ser explicado em função da necessidade de que os alunos fizessem mais inferências, uma vez que o conteúdo foi disposto nas cartas de forma sintética, exigindo maior participação para ampliar os conhecimentos sobre o assunto.

De fato, experiências com turmas anteriores mostraram que a apresentação de seminários com o mesmo conteúdo (DAI) causou pouco impacto sobre a atenção e o envolvimento dos alunos, sendo que muitos se dispersavam após a apresentação da sua equipe, não interagindo com as demais apresentações ou, até mesmo, saindo da sala de aula. Experiência similar foi verificada também pelos demais professores da disciplina de MAD. Neste caso particular, o curto tempo para a apresentação das várias doenças autoimunes e a expectativa de que a equipe poderia precisar destes conhecimentos para ganhar o jogo subsequente podem ter influenciado na atenção dedicada pelos alunos às apresentações. Por outro lado, a própria natureza do jogo que, como instrumento lúdico, exige uma entrega total do ser humano (corpo e mente), e assim absorve $\mathrm{o}$ aluno de maneira intensa e total ${ }^{11}$, faz com que este recurso aumente a participação efetiva em sala de aula.

\section{O jogo como experiência pedagógica}

Enquanto a elaboração e a apresentação das cartas ocorreram de forma bem tranquila, na execução do jogo percebeu-se certa hesitação por parte de alguns alunos, os quais relataram que no início pensaram que a atividade não funcionaria e que seria impossível juntar as quatro cartas de uma determinada doença. Posteriormente conseguiram perceber que seu funcionamento era possível e que a colaboração entre os colegas era indispensável para o sucesso. Neste sentido, muitos relataram que foi importante ter uma pessoa de cada dupla na equipe para ajudar a solucionar similaridades entre algumas doenças.

Dúvidas e inseguranças de alunos com a introdução deste tipo de metodologia tinham sido relatadas em alguns estudos ${ }^{6,9} \mathrm{e}$, por isso, já eram esperadas, uma vez que para muitos alunos essa fora a primeira experiência com jogos pedagógicos. Além disso, o fato de o jogo ter sido construído por 'várias mãos' contribuiu para esta insegurança, pois eles não tinham a noção do jogo como um todo. Nesse momento a professora teve que intervir motivando-os a experimentarem essa nova metodologia. Por outro lado, a existência de regras 
claras previamente estabelecidas e a empolgação de alguns alunos, os quais depois relataram experiências anteriores com jogos em sala de aula, foram cruciais para superar essa barreira e obter o sucesso do jogo.

Apesar da dificuldade inicial, durante a execução do jogo os alunos estavam completamente envolvidos com suas equipes, curiosos para verem as cartas, atentos, participativos, discutiam as cartas 'puxadas' com seus pares e se mostraram engajados em acertar as doenças. Os alunos estavam tão empolgados que não se aperceberam do tempo e, em depoimento, a maioria admitiu que a aula-jogo passou rápido e foi muito divertida, favoreceu a fixação dos mecanismos imunopatológicos e permitiu correlacionar os sinais e sintomas clínicos das doenças, ao diagnóstico e ao tratamento. O jogo foi avaliado por eles como um recurso válido e mais produtivo do que muitas aulas expositivas.

Cabe aqui destacar que não apenas os alunos, mas também professores hesitam em experimentar tais recursos $^{12}$, e, por este motivo, relatos de experiências como este se mostram relevantes, não somente por incentivar os professores a fazerem uso desses recursos pedagógicos, mas também por mostrarem que, apesar da elevada viabilidade técnica, estrutural e financeira, tais recursos encontram barreiras para sua implementação. Ficou claro na experiência aqui relatada que esses entraves podem ser contornados, inclusive com a ajuda dos próprios alunos.

O estímulo à competitividade, inerente aos jogos, é outro ponto que merece ser destacado. No início da atividade, os alunos estavam mais preocupados em verificar se ela funcionaria, entretanto, à medida que foram tomando segurança e se divertindo, tornaram-se mais competitivos, empenhando-se em vencer. Esse padrão foi observado em ambas as equipes por meio dos comportamentos e atitudes destacados a seguir.

Como já foi explicitado, a equipe vencedora deveria apresentar a DAI sem ler as cartas e sem errar. Assim, logo que a equipe vencedora iniciou a apresentação, a outra equipe a confrontou com perguntas e argumentos na tentativa de gerar dúvidas e inseguranças, induzindo a equipe adversária à infração da regra do jogo que diz respeito ao erro na apresentação da DAI. Entretanto, este comportamento gerou uma discussão saudável e, como os argumentos da equipe vencedora foram convincentes, sua vitória foi reconhecida e parabenizada ao final por seus 'oponentes'. A competitividade também se revelou na solicitação da equipe que não conseguiu vencer o jogo para que fosse realizada mais uma rodada a fim de tentar o empate. Este pedido foi prontamente aceito pela outra equipe, mas, devido à limitação de tempo, não foi possível realizá-la no mesmo dia.

A competição faz parte do homem e, historicamente, os jogos foram desenvolvidos para explorar este aspecto, mas no ambiente acadêmico tem se revelado como cerne de dúvidas e discussões. Situações competitivas, no entanto, podem permitir que os educandos aprendam a lidar com pequenas frustrações e conquistas, comuns na vida real. Entretanto, é importante repensar as estratégias utilizadas no jogo e direcioná-las para a cooperação mútua, em que os sujeitos envolvidos se apoiam para vencer um obstáculo e não o oponente ${ }^{13}$. De acordo com Amaral, ${ }^{14}$ os jogos permitem ao aluno uma série de experiências, como a de confrontamento de pontos de vista, defesa de interesses, participação em discussão, vivência da crise e do conflito na tomada de decisão, o que em conjunto contribui para a formação pessoal, ética e profissional. Cabe destacar que, em nossa experiência com o ImunoDAI, a presença constante de brincadeiras, risos e provocações revelou o clima amistoso do jogo e, em nenhum momento, a competitividade revestiu-se de ponto negativo ou comprometeu a busca do objetivo principal de agrupar as cartas para a caracterização de uma doença autoimune, tendo como premissa a cooperação de todos os envolvidos. O tom amistoso da disputa se revelou na pronta aceitação pela equipe vencedora em realizar mais uma rodada para que a outra equipe tentasse o empate, o que de fato ocorreu sem repercussões.

Uma das grandes vantagens da utilização dejogos como ferramentas educacionais éque ojogo pode ser repetido em sequência ou mesmo em outro momento. Por exemplo, ser reexecutado antes da prova como uma forma de fixação ou de revisão dos conteúdos e dispersão do estresse. Além disso, a repetição do jogo é frequentemente mais rápida, pois os alunos já conhecem as regras e o tema, bem como rapidamente se organizam para iniciar. 
Na experiência aqui relatada não foi possível realizar uma segunda rodada do ImunoDAI no mesmo dia devido à limitação de tempo, já que toda a atividade durou aproximadamente $4 \mathrm{~h}$. No entanto, sabendo que alguns professores não dispõem desse tempo de aula, sugerimos que a apresentação dos seminários/cartas seja realizada em um dia e o jogo seja executado em outro. Outra sugestão é dividir a turma em quatro equipes, neste caso o tempo de execução do jogo será de 50 minutos, e o jogo ficará mais dinâmico e competitivo.

É imperativo destacar que o tempo é importante em todas as etapas do jogo, desde sua concepção criativa e elaboração até a execução em si e, além disso, este tempo deve ser adequado para alunos e professores. Como pontua Fontoura ${ }^{15}$, "Um professor ao confeccionar e/ou escolher um jogo para aplicar em suas turmas necessita de um objetivo principal e tempo para pesquisar, de modo que interligue o ensino lúdico ao conhecimento pedagógico; desta forma, a utilização de um jogo proporciona ao docente mais conhecimento e enriquecimento de suas diretrizes pedagógicas".

Segundo Rizzi1 ${ }^{11}$, os jogos são ferramentas pedagógicas que desenvolvem a espontaneidade mesmo diante de regras a serem seguidas, sendo que as regras servem para ajudar o aluno a se organizar e, portanto, possuem função ética e social. Além disso, os jogos possibilitam a repetição e a exploração de novas formas de jogar. Durante a execução do ImunoDAI, os alunos propuseram modificações na qualidade das cartas, novas regras e até novas formas de jogar para otimizar o tempo. Todas as sugestões eram exequíveis, revelando, desta forma, o envolvimento dos alunos e a sua apropriação do jogo. Esse fato também atestou a flexibilidade de execução do jogo como mais uma de suas vantagens.

As sugestões de melhorias feitas pelos alunos se deram em relação à qualidade de impressão, sobretudo das fotografias. No que diz respeito às regras do jogo, as sugestões apresentadas por eles tinham, em sua maioria, o efeito de otimizar o tempo para permitir mais rodadas. De fato, várias ideias surgem durante a execução de jogos educativos e não devem, de forma alguma, ser descartadas, pois uma característica importante dessas ferramentas interativas é que elas são adaptáveis a diversas realidades. Muitas vezes, elas são criadas para uma disciplina, mas podem ser utilizados em outras, a depender do tema e dos objetivos propostos. Além disso, essas ferramentas se tornam muito mais eficientes quando os alunos se apropriam delas e contribuem para sua melhoria.

\section{O professor como mediador do processo de ensino e aprendizagem e as dificuldades deste novo papel}

É importante destacar que, durante as apresentações dos temas e execução do jogo, a professora assumiu o lugar de mediadora do processo de aprendizagem, estimulando reflexões e repercussões sobre o tema e delegando aos alunos a responsabilidade de solucionar as dúvidas que surgiam. Desse modo, a professora respondeu apenas as questões que não foram resolvidas pelo grupo. Ao empregar os jogos como uma estratégia de ensino, o professor assume a posição de mediador pedagógico, ou seja, deixa de ser um mero transmissor de conhecimentos e adota o comportamento de orientador, facilitador e motivador da aprendizagem. Essa atitude visa a auxiliar o estudante a chegar aos objetivos previamente delineados e, além disso, leva-o a desenvolver valores, atitudes e habilidades que lhe permitam crescer como pessoa e em seu futuro profissional. Para alcançar tais objetivos, no entanto, o mediador pedagógico deve utilizar metodologias de ensino e materiais didáticos adequados segundo a linguagem e a complexidade dos conteúdos e que proporcionem interações e reflexões múltiplas, participação colaborativa, tomada de decisão e autonomia. Tais habilidades são indispensáveis aos estudantes de medicina e estão em acordo com as Diretrizes Curriculares Nacionais do curso ${ }^{16-18}$.

Apesar da boa receptividade do ImunoDAI, é importante pontuar que a proposta de elaboração do jogo dividiu opiniões entre os alunos e foi, primeiramente, rejeitada por metade deles, pois acreditavam que a elaboração desse instrumento seria muito mais laboriosa do que a preparação de seminários, com cuja metodologia eles já estavam acostumados. Por outro lado, os estudantes que concordaram 
prontamente com a proposta acrescentaram que estavam cansados de preparar seminários em todas as disciplinas. Para resolver o impasse, a professora insistiu no projeto e apresentou alguns slides contendo os temas que seriam abordados, exemplos das cartas, esquemas e quadros, bem como especificações sobre como elaborar e apresentar o jogo e a forma de avaliação. Foi necessário explicar aos alunos que os pontos abordados seriam os mesmos de um seminário, mas que a forma de execução seria muito mais dinâmica e divertida para eles. Esses argumentos foram acatados pela turma e, por fim, todos os alunos concordaram em experimentar essa nova ferramenta.

A rejeição inicial (momento em que a proposta foi apresentada aos alunos) a este tipo de recurso pedagógico não é relatada pelos autores em seus estudos, mas na prática verificamos que ela é muito frequente, tanto para os jogos quanto para os demais recursos (paródias, cartilhas, filmes etc.), sendo este o principal desafio a ser superado. Em paralelo, essa rejeição revela que, apesar de alunos e professores concordarem que as aulas tradicionais precisam ser modificadas e incrementadas com novos elementos que envolvam o aluno e o façam participar ativamente de todos os momentos da aula, há um receio generalizado de experimentar novas metodologias. Esse receio provavelmente se deve à falta de experiência com essas novas metodologias, à ausência de um repertório de metodologias descritas de forma clara para possibilitar sua reprodução e, principalmente, ao medo de falhar. Assim, muitos professores se acomodam com metodologias às quais já estão acostumados e, portanto, seguros em replicar.

Para obter sucesso na experimentação de novas metodologias de aprendizagem é muito importante planejar todos os passos de sua execução, dando especial atenção à seleção do tema, tempo de execução, materiais necessários, regras e formas de avaliação (quando for o caso), para que os alunos se motivem a participar e sintam que serão avaliados de forma justa. Além disso, cabe enfatizar que alguns temas se harmonizam melhor com determinados tipos de jogos e que as diferentes turmas de alunos apresentam percepções e aceitação distintas, portanto, é necessário experimentar. Por fim, e não menos importante, deve-se focar nos objetivos pedagógicos, pois o uso de jogos educativos deve ser compreendido como uma forma lúdica de conduzir determinados conteúdos didáticos para alcançar um objetivo pedagógico planejado e congruente com o projeto pedagógico do curso. Dessa forma, o professor deve agir como mediador entre os alunos e os conteúdos da disciplina tendo o jogo como uma ferramenta facilitadora de diversas interações.

\section{Considerações finais}

Os jogos pedagógicos sempre estiveram presentes na educação infantil, mas só recentemente têm ganhado espaço nas universidades, onde alguns educadores começam a utilizar esta ferramenta lúdica em disciplinas como histologia, imunologia e morfologia, entre outras. A despeito do crescente interesse nesses recursos, a maioria das experiências exitosas são publicadas de forma incompleta em sites institucionais e anais de reuniões científicas e congressos, sendo poucos os trabalhos publicados em revistas tradicionais, o que dificulta seu referenciamento e replicação, como foi o caso de alguns jogos de imunologia. Por essa razão, inciativas de compartilhar os produtos das criações intelectuais, bem como descrever as experiências positivas e negativas com o uso dessas ferramentas pedagógicas, devem ser incentivadas para que os professores possam fazer uso dessas ideias.

Em nossa experiência com o uso do ImunoDAI, verificamos que esse instrumento educativo pode beneficiar o processo de ensino-aprendizagem de alguns conteúdos, principalmente aqueles extensos e complexos, como é o caso do tema Doenças Autoimunes. Os benefícios alcançados com o jogo referem-se à otimização do tempo em sala de aula, maior envolvimento e atenção dos alunos, e maior interação dos alunos com os conteúdos e colegas, mostrando-se superior às aulas teóricas.

No que diz respeito à experiência aqui relatada, o impacto do jogo sobre a aprendizagem efetiva não pôde ser avaliado, pois este recurso foi utilizado na penúltima aula do módulo de imunologia básica 
como forma de revisar e integrar os conteúdos da disciplina. Como esta disciplina se ocupa em abordar os mecanismos básicos da resposta imunológica, as DAI não seriam contempladas em virtude da carga horária. Dessa forma, o jogo ImunoDAI proporcionou o primeiro contato dos alunos com a imunologia clínica, disciplina que será abordada nos semestres seguintes. No futuro esperamos apresentar o impacto do uso deste instrumento pedagógico como forma de facilitação do aprendizado, evidenciado pela melhoria do desempenho dos alunos nas avaliações institucionais.

Sob a perspectiva docente, diante do comportamento dos discentes, ficou demonstrado que os alunos ficaram felizes com o produto final e que se apropriaram do jogo de diversas formas, participaram de forma ativa e colaborativa interagindo com os colegas, fixaram os conteúdos de forma descontraída e demonstraram em atitudes e palavras que este recurso é válido e mesmo superior às aulas expositivas. Nesta mesma perspectiva, a elaboração e utilização do ImunoDAI configurou-se como uma experiência exitosa que oportunizou conhecimento, aprendizado, mudança de comportamento, colaborações e motivação para modificar a prática docente.

A execução do jogo ImunoDAI como proposta de um método ativo de ensino-aprendizagem na disciplina MAD-Imunologia permitiu alcançar os seguintes objetivos pedagógicos:(1) promover autonomia, ao conduzir os alunos a realizarem a pesquisa dos conteúdos, selecionar e estudar o assunto para apresentar na forma de cartas e de seminários; (2) promover a integração dos conhecimentos adquiridos no decorrer do módulo de Imunologia Básica e suas inter-relações com as demais disciplinas da MAD; (3) proporcionar um meio para cooperação mútua, discussão e argumentação, já que os alunos compartilharam os conhecimentos sobre as demais doenças autoimunes com seus pares; (4) promover a reflexão e a tomada de decisões, pois o grupo tinha que discutir com seus pares e decidir sobre as direções a tomar; e (5) promover a criatividade, uma vez que os alunos foram estimulados a traduzir o conhecimento técnico-acadêmico sobre DAI para uma forma visual, de fácil compreensão e assimilação. Todas essas habilidades e competências são importantes para o desenvolvimento do futuro médico que terá que trabalhar em conjunto com o paciente e seus familiares, bem como com outros profissionais da área da saúde para tomar decisões importantes sobre seus pacientes.

Dessa forma, conclui-se que jogos pedagógicos contribuem enormemente para melhorar a qualidade das aulas no ensino superior, facilitando a apresentação e a fixação de conteúdos extensos, promovendo a interdisciplinaridade, além de propiciar o desenvolvimento de habilidades que não podem ser desenvolvidas em aulas expositivas tradicionais e, por isso, merecem um espaço cada vez maior na prática pedagógica.

\section{Referências}

1. Júnior DM, Araújo JAP, Catelan TT, Souza AWS, Cruvinel WM, Andrade LEC, Silva NP. Sistema Imunitário - Parte II Fundamentos da resposta imunológica mediada por linfócitos T e B. Rev Bras Reumatol [Internet]. 2010 [citado em 2019 jun 15];50(5):552-80. Disponível em: http://www.scielo.br/ pdf/rbr/v50n5/v50n5a08.pdf.

2. Abbas AK, Lichtman AH, Pillai S. Imunologia Celular e Molecular. 7. ed. Rio de Janeiro: Elsevier; 2012.

3. Miranda S. No fascínio do jogo, a alegria de aprender. Ci Hoje. 2002;28(168):64-66.

4. Moratori PB. Por que utilizar jogos educativos no processo de ensino aprendizagem? [trabalho conclusão de disciplina]. Rio de Janeiro: Universidade Federal do Rio de Janeiro; 2003.

5. Morais AF, Oliveira L, Funayama JC. O jogo da memória como recurso lúdico para o ensino de histologia básica. [Internet]. In: 7a Jornada Científica e tecnológica IFSULDEMINAS. 2015 nov. 12-13 [citado em 2019 jul. 16]; Poços de Caldas-MG: IFSULDEMINAS; 2015. Disponível em: https://jornada.ifsuldeminas. edu.br/index.php/jcpcs/jcpcs/paper/viewFile/1152/899.

6. Pereira JC. Jogos educativos na saúde: avaliação da aplicação dos jogos "perfil parasitológico" e "perfil microbiano". R. Saude Comun. [Internet]. 2015 [citado em 2019 jun 15];11(1):2-9. Disponível em: http://periodicos2.uesb.br/index.php/rsc/article/view/333/270. 
7. Rabelo RS, Mota EF. Linfócitos em ação: jogo pedagógico e sua importância no ensino de imunologia. [Internet]. In: V Encontro Regional de Ensino de Biologia do Nordeste - V EREBIO/NE. 2013 ago 2123 [citado em 2019 jul. 16]; Natal, RN: SBEnBio, 2013. Disponível em: http://www.sbenbio.org.br/ verebione/docs/60.pdf.

8. $\quad$ Rosadas C. "Quem Sou Eu? Jogo dos Vírus": Uma Nova Ferramenta no Ensino da Virologia. Rev Bras Educ Méd [Internet]. 2012 [citado em 2019 jun 15];36(2):264-8. Disponível em: http://www.scielo.br/ pdf/rbem/v36n2/16.pdf.

9. Topanotti LR, Lima DM, Silva MS. Jogos no ensino superior: uma ferramenta para o ensino de morfologia vegetal. [Internet]. In: I Congresso de Ciência e Tecnologia da UTFPR - campus dois vizinhos, V seminário: sistemas de produção agropecuária e I simpósio de ciências florestais e biológicas. 2011 out.17-18. [citado em 2019 jul. 16]; Paraná: UTFPR, 2011. Disponível em: http://revistas.utfpr.edu.br/ dv/index.php/CCT DV/article/view/564/346.

10. Araújo MFM, Almeida MI, Silva RM. AIDS/Educação e prevenção: proposta metodológica para elaboração de jogos educativos. R. Bras Enfer [Internet]. 2000 [citado em 2019 jul. 16];53(4): 607-13. Disponível em: http://www.scielo.br/pdf/reben/v53n4/v53n4a16.pdf.

11. Rizzi L, Haydt RC. Atividades lúdicas na educação da criança. São Paulo: Ed. Ática; 2001.

12. Lima VV, Komatsu RS, Padilha RQ. Desafios ao desenvolvimento de um currículo inovador: a experiência da Faculdade de Medicina de Marília. Interface Comunic, Saúde, Educ. 2003;7(12):175-84.

13. Kemmer AVM. A influência da competição na vida escolar do educando. [Internet]. In: IV Encontro Fluminense de Educação Física Escolar; 2000 jun. 16-17 [citado em 2019 jul. 16]. Niterói, RJ: UFF; 2000. p. 13-5. Disponível em: http://cev.org.br/biblioteca/a-influencia-da-competicao-na-vida-escolar-do-educando.

14. Amaral JD. Jogos Cooperativos. São Paulo: Phorte, 2004.

15. Fontoura MTS, Lima, RF, Santos AS, Pereira RMM. Aplicabilidade de jogos educativos com alunos do segundo segmento do ensino fundamental do Instituto de aplicação Fernando Rodrigues da Silveira. [Internet]. In: VII Encontro Nacional de Pesquisa em Educação em Ciências; 2009 [citado em 2019 jul. 16] Florianópolis, SC: UFMG; 2009. Disponível em:http://posgrad.fae.ufmg.br/posgrad/viienpec/ pdfs/1556.pdf.

16. Bulgraen VC. O papel do professor e sua mediação nos processos de elaboração dor conhecimento. Rev Conteúdo. 2010;1(4):30-8.

17. Mallmann EM, Catapan AH. Materiais didáticos em educação a distância: gestão e mediação pedagógica. Linhas Florianópolis. 2007;8(2):63-75.

18. Ministério da Educação (BR). Resolução No 3, de 20 de junho de 2014. Institui Diretrizes Curriculares Nacionais do Curso de Graduação em Medicina e dá outras providências [Internet]. 2014 [citado em 2019 jul. 16]. Disponível em: http://portal.mec.gov.br/index.php?option=com docman\&view $=$ download\&alias=15874-rces003-14\&category slug=junho-2014-pdf\&Itemid=30192. 